\title{
Influence of the dissolved hydrogen concentration on the radioactive contamination of the primary loops of DOEL-4 PWR using the OSCAR code
}

\author{
Mehdi Gherrab ${ }^{1, *}$, Frédéric Dacquait ${ }^{1}$, Dominique You $^{2}$, Etienne Tevissen ${ }^{1}$, Raphaël Lecocq ${ }^{3}$, and Kim Schildermans ${ }^{3}$ \\ ${ }^{1}$ CEA, DEN, 13108 Saint-Paul Lez Durance, France \\ ${ }^{2}$ CEA, DEN, 91191 Gif-sur-Yvette, France \\ ${ }^{3}$ ENGIE, LABORELEC, 1630 Linkebeek, Belgium
}

Received: 17 January 2019 / Received in final form: 9 June 2019 / Accepted: 22 January 2020

\begin{abstract}
Corrosion products are generated in the primary circuit during normal operation and are activated in the core. Those activated corrosion products, mainly ${ }^{58} \mathrm{Co}$ and ${ }^{60} \mathrm{Co}$ (coming respectively from the activation of ${ }^{58} \mathrm{Ni}$ and ${ }^{59} \mathrm{Co}$ ), are then transported by the primary fluid and deposited on the out-of-flux surfaces (steam generators, primary coolant pipes...). To minimize this radioactive contamination, one needs to understand the behavior of corrosion products by carrying out measurements in PWRs and test loops combined with a reactor contamination assessment code named OSCAR. The aim of this article is to evaluate the influence of the change in the Dissolved Hydrogen (DH) concentration on the contamination of the primary loops of DOEL-4 PWR, a Belgian unit. After the description of the principle of the OSCAR V1.3 code, its use is illustrated with the simulation of DOEL-4. Finally, those calculations are compared to autoclave experiments called DUPLEX with thermodynamic and chemical conditions closed to those observed in PWRs. OSCAR V1.3 calculations show that an increase in the $\mathrm{DH}$ concentration results in a decrease in ${ }^{58} \mathrm{Co}$ surface activities. These results are consistent with those from the DUPLEX experiments. Finally, an increase of the DH concentration is then recommended in operating PWRs to reduce the ${ }^{58}$ Co surface contamination.
\end{abstract}

\section{Introduction}

Understanding the PWR primary circuit contamination by corrosion products, fission products and actinides are a crucial issue for reactor operation and design.

The OSCAR code takes into account the chemical and physical mechanisms in operating reactors or at design stage. This code has been developed with this aim by CEA in collaboration with EDF and Framatome, and has actually been used since the early seventies [1].

OSCAR is a reliable tool for PWRs (also used for EPR, SFR, ITER [2], decommissioning, etc.) calibrated and validated with a complete database of contamination measurements on EDF fleet [3,4].

Water chemistry has an influence on corrosion [5] of the main materials (especially nickel-based alloys); in the Belgian PWRs the average dihydrogen concentration used is around $30 \mathrm{~mL} / \mathrm{kg}$, which is not the best value to mitigate stress corrosion cracking of the materials. It also has an influence on dissolution/precipitation mechanisms involved in contamination.

\footnotetext{
* e-mail: mehdi.gherrab@cea.fr
}

Water chemistry control may allow reducing significantly the radioactive contamination in the primary loops and therefore facilitating maintenance operations.

In this field, dissolved hydrogen (DH) plays a critical role in limiting the presence of oxidizing species due to water radiolysis [6]. Increasing DH could also reduce core internals cracking [7].

The aim of this study is to evaluate the influence of the $\mathrm{DH}$ on the contamination of the primary loops using the OSCAR code.

This study presents the results of a sensitivity analysis, using the 1.3 version of the OSCAR code, of the contamination of the primary loops of DOEL-4 PWR with DH concentrations ranging between 15 and $70 \mathrm{~mL} / \mathrm{kg}$.

The variation of the surface contamination in ${ }^{58} \mathrm{Co}$ and ${ }^{60} \mathrm{Co}$ are calculated on the hot legs, crossover legs and steam generators $(\mathrm{SG})$ tubing. In order to explain those variations, the equilibrium $\mathrm{Ni}$ concentration in solution (assuming the thermodynamic equilibrium in the coolant with respect to the considered oxide inner or outer) and the Ni concentrations in solution are calculated in the SG and fuel regions.

The Ni dissolution (from the deposit/outer oxide to the ions) and the corrosion release (directly from the metal to the ions) flux of the SG are also calculated. 


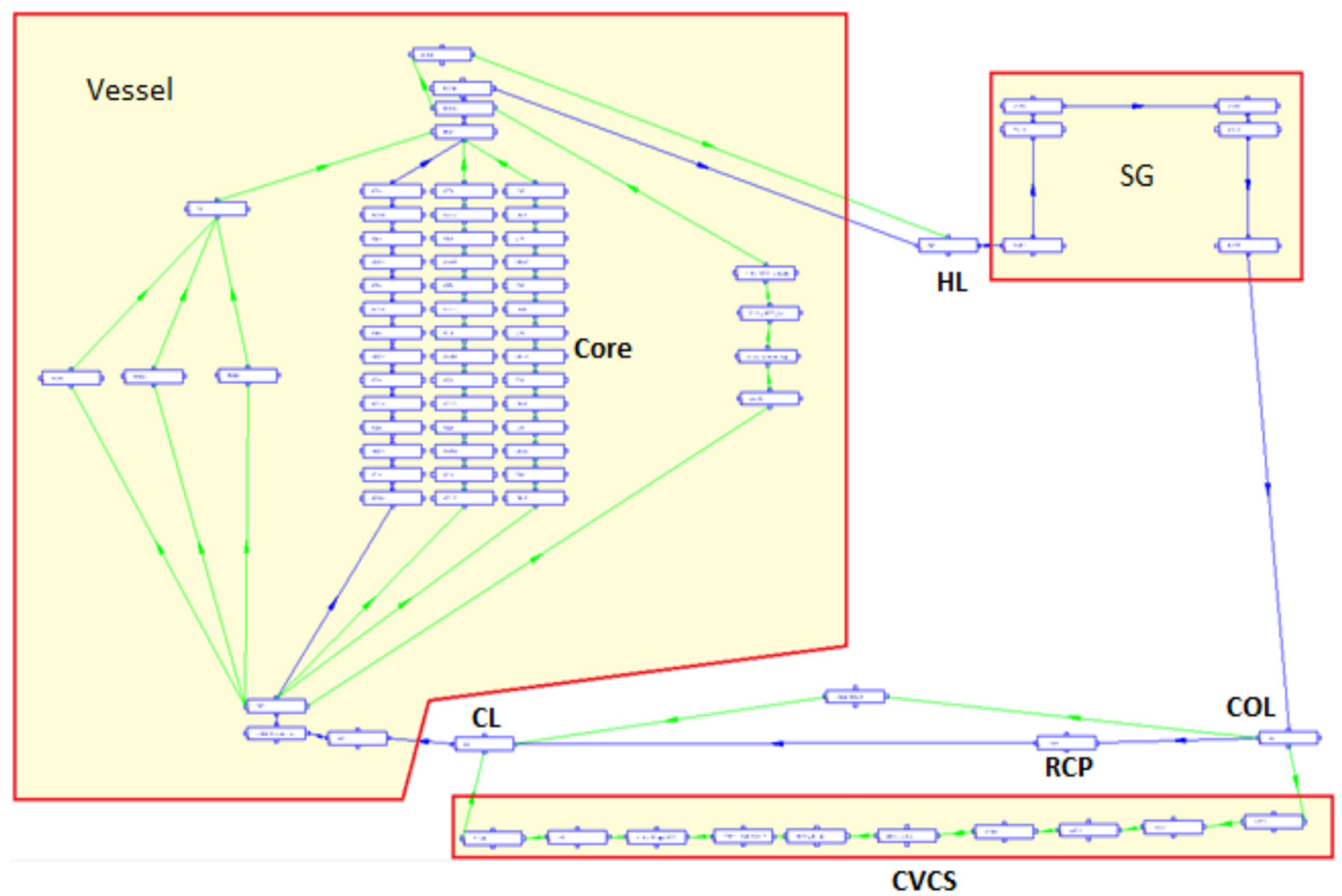

Fig. 1. Control volumes of a typical PWR (HL: Hot leg / SG: Steam generator / COL: Crossover leg / RCP: Reactor coolant pump / CL: Cold leg).

The equilibrium concentration in solution of each chemical element and the oxide speciation of the deposit are calculated by the OSCAR chemistry module, PHREEQCEA (a version of the PHREEQC code [8] extended to the PWR temperature range) in combination with a thermodynamic database developed by the CEA [9]. PHREEQCEA determines the composition of the ideal solid solution (mixed oxides and any pure solid phases possibly in excess) and the equilibrium concentration in solution of each species in relation to the chemical conditions $\left(\mathrm{pH}, \mathrm{H}_{2}, \mathrm{O}_{2}\right)$, the coolant temperature and the masses of the metallic element of the deposit in each regions. One may note in this article that the dominant species in solution is $\mathrm{NiOH}^{+}$for $\mathrm{Ni}$ and $\mathrm{Co}(\mathrm{OH})_{2}$ for Co.

This article also presents autoclave experiments to evaluate the impact of several DH values on alloy 690 material, which are compared to simulation results.

\section{The OSCAR Code}

For corrosion products, the source term is the consequence of the corrosion of the base metals. The corrosion leads to the formation of oxide layers and induces the release of dissolved metals in the primary coolant. The main metallic elements taken into account are those composing the main alloys found in PWR primary system: $\mathrm{Ni}, \mathrm{Co}, \mathrm{Fe}$, $\mathrm{Cr}$ and $\mathrm{Mn}$.

The OSCAR modeling is based on the subdividing of the PWR circuits into elementary regions (cf. Fig. 1):
- each region is defined by its geometric, thermal, neutron and hydraulic characteristics and by its base metal. These characteristics are the main input data required for an OSCAR simulation;

- each region is characterized by six media: the base metal, the inner oxide layer, the deposit/outer oxide layer, particles, ions (species in solution) and purification media.

The OSCAR calculation consists in the resolution of the mass balance equations for each isotope in each medium of each region using the following equation:

$$
\frac{\partial M_{i}^{j}}{\partial t}=\sum_{\text {Source }} J_{m}-\sum_{\text {Sink }} J_{m}+\dot{m}_{\text {in }}-\dot{m}_{\text {out }}
$$

with $M_{i}^{j}$ the mass of the isotope $(i)$ in a given medium $(j)$ $[\mathrm{kg}], t$ the time $[\mathrm{s}],\left(\dot{m}_{\text {in }}-\dot{m}_{\text {out }}\right)$ the convection term $\left[\mathrm{kg} \cdot \mathrm{s}^{-1}\right]$ and $J_{\mathrm{m}}$ the mass flux between two media $\left[\mathrm{kg} \cdot \mathrm{s}^{-1}\right]$. The variations of the concentrations of the species in the six media result from corrosion, release diffusion, convection, activation, purification, radioactive decay mechanisms and the exchange flux between the media.

Figure 2 describes the different media and mass rates in a region. The main mechanisms involved in the transfers between the six media are dissolution/precipitation (between deposit/outer oxide and ions), erosion, deposition (between deposit/outer oxide and particles) and release directly from the metal to the ions. Dacquait et al. [3] have reported a detailed description of these mechanisms. 




Fig. 2. Mass transfers between the different media in a region.

Table 1. Weight composition of alloy 600 and 690 tubed steam generators.

\begin{tabular}{lll}
\hline $\begin{array}{l}\text { Composition of tubed steam } \\
\text { generators (wt. \%) }\end{array}$ & Alloy 600 & Alloy 690 \\
\hline $\mathrm{Ni}$ & 74.95 & 60.2 \\
$\mathrm{Fe}$ & 9 & 9.77 \\
$\mathrm{Cr}$ & 15 & 28.91 \\
$\mathrm{Mn}$ & 1 & 0.3 \\
$\mathrm{Co}$ & 0.05 & 0.009 \\
\hline
\end{tabular}

The dissolution of a deposit occurs when the concentration of a soluble species in solution is less than its equilibrium concentration in solution. Soluble species precipitate when their concentration in the coolant reaches their equilibrium concentration in solution.

\section{Operating parameters of DOEL-4}

DOEL-4 is a 3-loop PWR equipped with alloy 600 tubed steam generators then with alloy 690 after the steam generator replacement at cycle 11 . The weight composition of alloy 600 and 690 is reported in Table 1 .

The structure of the DOEL-4 primary circuit is modeled by control volumes using the design data of the reactor (wetted surfaces, hydraulic diameters, material compositions, nominal temperatures...).

Operating cycles of DOEL-4 are simulated using the 1.3 version of the OSCAR code with the real hydrogen concentration for cycles 1 to 22 . Three additional reference cycles are calculated for DOEL-4 to test various hydrogen concentrations.

The parameters of the reference cycles are reported in Table 2.

The operating parameters (Power, $\mathrm{C}_{\mathrm{B}}, \mathrm{C}_{\mathrm{Li}}, \mathrm{C}_{\mathrm{H} 2}, \mathrm{C}_{\mathrm{O} 2}$ ) are given in Figure 3 .
The last three cycles correspond to the reference cycles with a simulated shutdown at the end of each cycle.

Power is set to $100 \%$, the boron concentration decreases at each cycle from $1424 \mathrm{pm}$ to $157 \mathrm{ppm}$, the lithium concentration decreases from $3.35 \mathrm{ppm}$ to $0.59 \mathrm{ppm}$. Concerning hydrogen, three cases are studied 15, 30 and $70 \mathrm{~mL} / \mathrm{kg}$ with a stable value during the three cycles for each case. The oxygen peaks are due to the simulated shutdowns.

\section{Influence of the DH concentration on the calculated contamination of DOEL-4 PWR}

Calculated ${ }^{58} \mathrm{Co}$ and ${ }^{60} \mathrm{Co}$ surface activities inside the primary system (Hot leg, Crossover leg, hot side of the steam generator tubing and cold side of the steam generator tubing regions) are presented in Figures 4-7.

Concerning ${ }^{58} \mathrm{Co}$, it is clear that an increase of the $\mathrm{DH}$ value leads to a decrease in the surface activities in the primary system for the last three cycles of DOEL-4. Concerning ${ }^{60} \mathrm{Co}$, the decrease tendency is slight.

For $\mathrm{DH}$ concentrations of 15 and $70 \mathrm{~mL} / \mathrm{kg}$, the relative variations of the deposited activities (of ${ }^{58} \mathrm{Co}$ and ${ }^{60} \mathrm{Co}$ ) on the out-of-core surfaces at the end of cycle 25 compared to a $\mathrm{DH}$ value of $30 \mathrm{~mL} / \mathrm{kg}$ are presented in Table 3 .

The increase in the $\mathrm{DH}$ concentration up to $70 \mathrm{~mL} / \mathrm{kg}$ leads to a decrease in the deposited activities of ${ }^{58} \mathrm{Co}$ and ${ }^{60} \mathrm{Co}$, respectively, by $57 \%$ and $4 \%$.

On the contrary, a decrease in the $\mathrm{DH}$ down to $15 \mathrm{~mL} / \mathrm{kg}$ leads to an increase of the deposited activities of ${ }^{58} \mathrm{Co}$ and ${ }^{60} \mathrm{Co}$, respectively, by $74 \%$ and $4 \%$.

This table shows that the DH concentration significantly affects the ${ }^{58} \mathrm{Co}$ contamination of the out-of-flux surfaces and to a negligible extent the ${ }^{60} \mathrm{Co}$ contamination.

It also shows that an increase in the $\mathrm{DH}$ concentration (from 15 to $70 \mathrm{~mL} / \mathrm{kg}$ ) leads to a decrease of the deposited activities of ${ }^{58} \mathrm{Co}$ and ${ }^{60} \mathrm{Co}$.

\section{Comparison between the $\mathrm{Ni}$ equilibrium concentrations and $\mathrm{Ni}$ concentrations inside the core and steam generator tubing regions}

When the $\mathrm{DH}$ concentration goes from 15 to $70 \mathrm{~mL} / \mathrm{kg}$, the $\mathrm{Ni}$ equilibrium concentration and $\mathrm{Ni}$ concentration inside the hottest core region change (see Fig. 8).

For $\mathrm{DH}$ concentrations of 15 and $30 \mathrm{~mL} / \mathrm{kg}, \mathrm{Ni}$ equilibrium concentrations are equal. Ni concentrations are above $\mathrm{Ni}$ equilibrium concentrations which means that $\mathrm{Ni}$ tends to precipitate in the hottest core region and even more for $15 \mathrm{~mL} / \mathrm{kg}$ (widening of the gap between $\mathrm{Ni}$ equilibrium concentration and $\mathrm{Ni}$ concentration) than for $30 \mathrm{~mL} / \mathrm{kg}$. This ${ }^{58} \mathrm{Ni}$ that precipitates on the fuel rods is activated in ${ }^{58} \mathrm{Co}$, eroded and transported by the primary fluid, makes deposits on the out-of-flux surfaces, for example in the steam generator (see Fig. 7). 
Table 2. Parameters of the reference cycles.

\begin{tabular}{llllll}
\hline Nominal power & Cycle duration & $\mathrm{B}_{\text {init }}$ & $\mathrm{Li}_{\text {init }}$ & $\mathrm{DH}$ & $\mathrm{pH}$ \\
\hline $100 \%$ & 473 days & $1424 \mathrm{ppm}$ & $3.35 \mathrm{ppm}$ & $15-30-70 \mathrm{~mL} / \mathrm{kg}$ & $7.2\left(\right.$ at $\left.312^{\circ} \mathrm{C}\right)$ \\
\hline
\end{tabular}
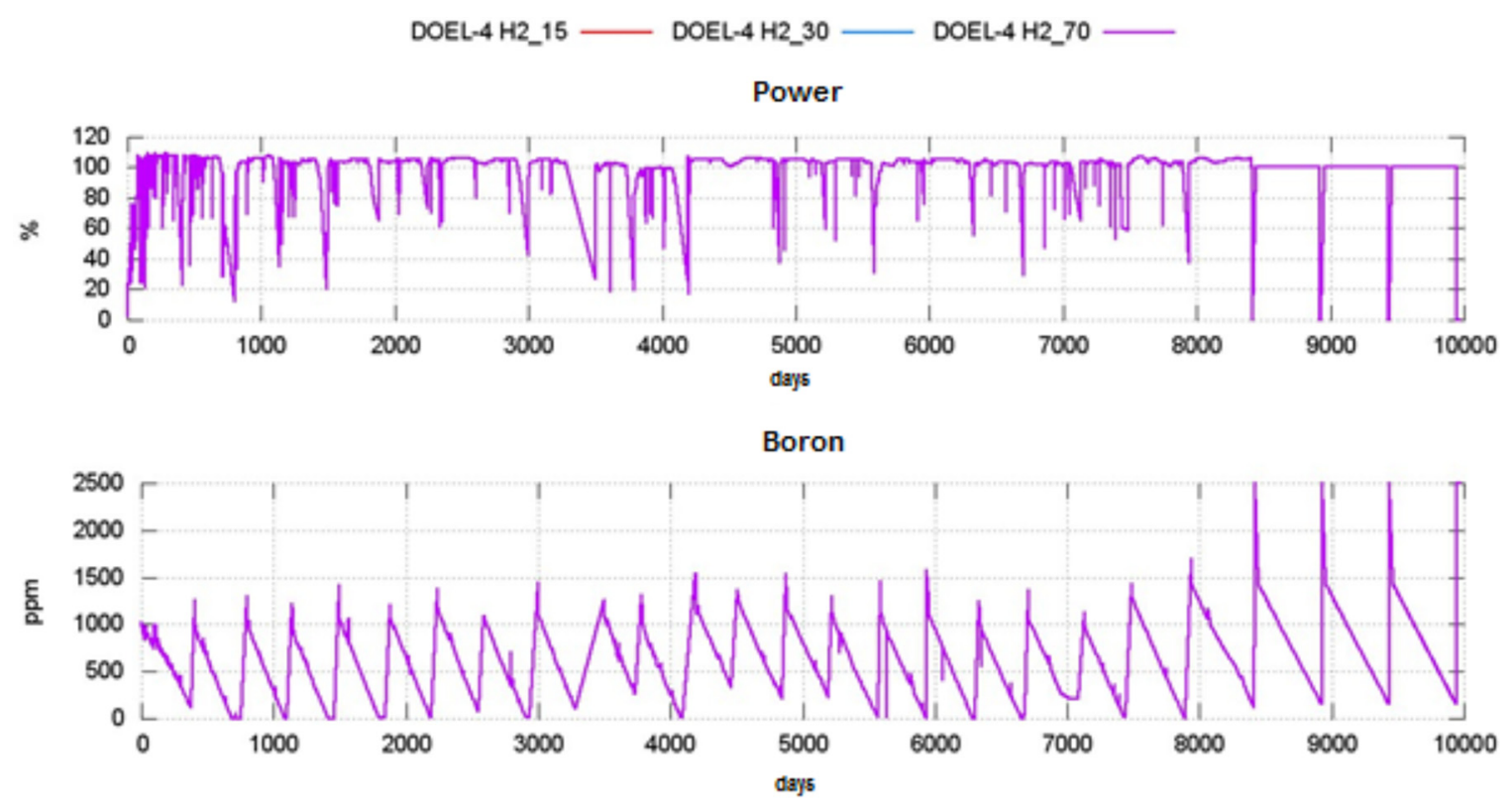

Lithium

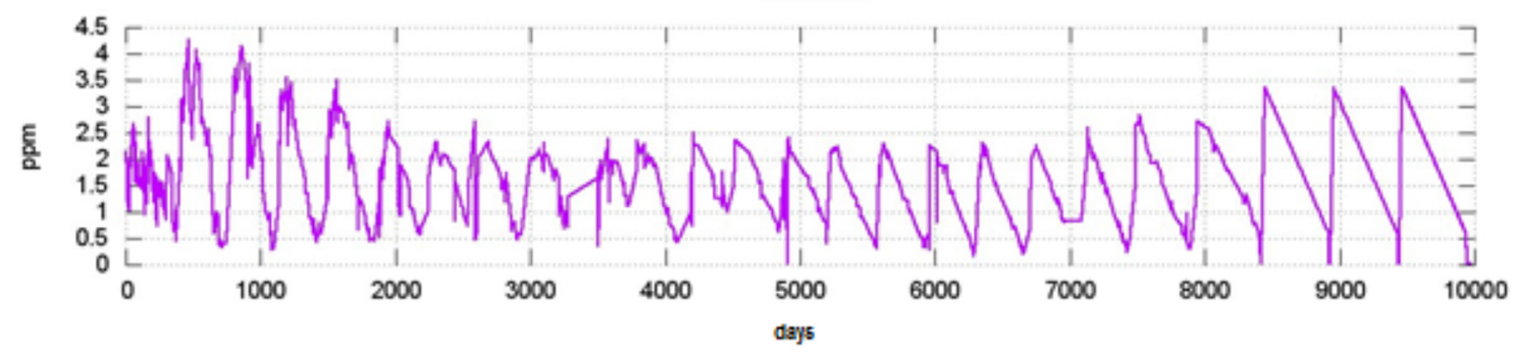

Hydrogen

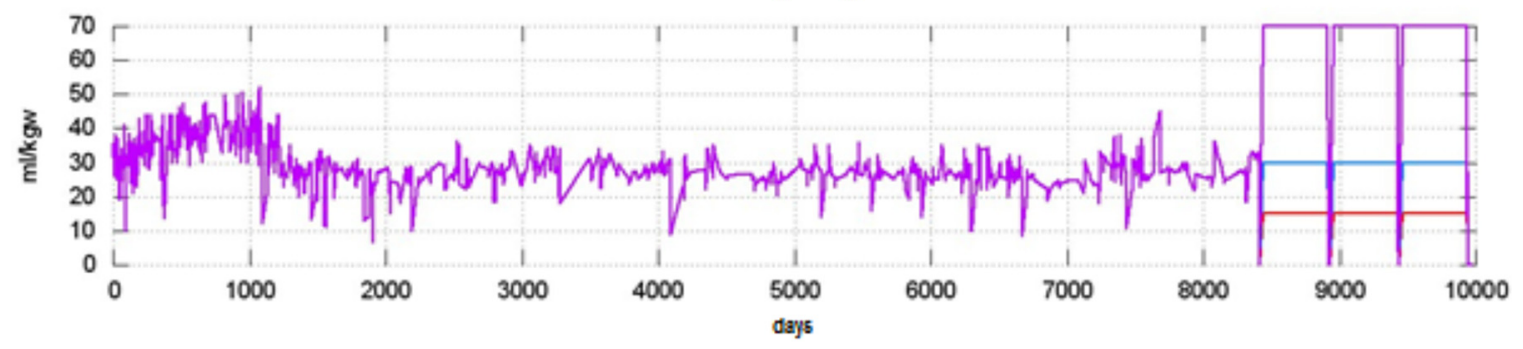

Oxygen

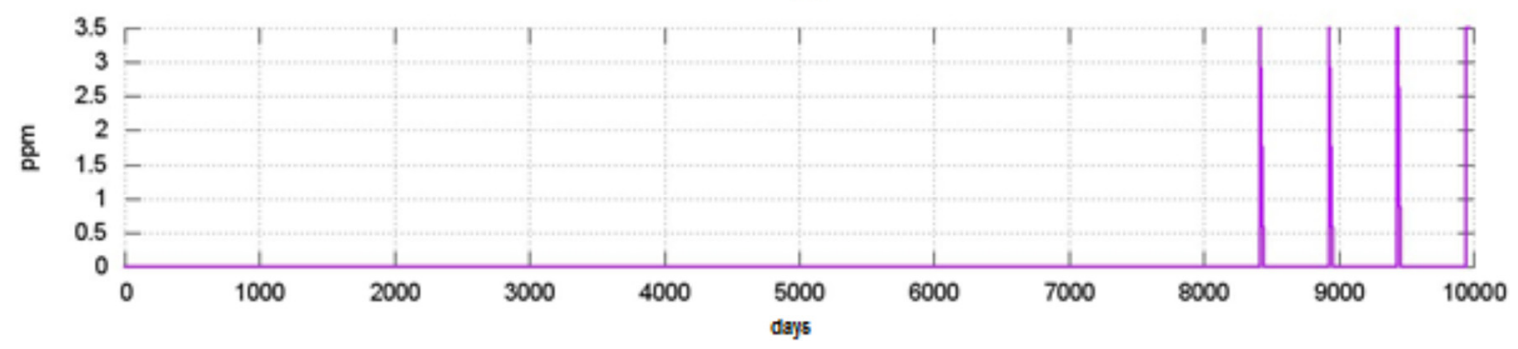

Fig. 3. DOEL-4 operating parameters. 

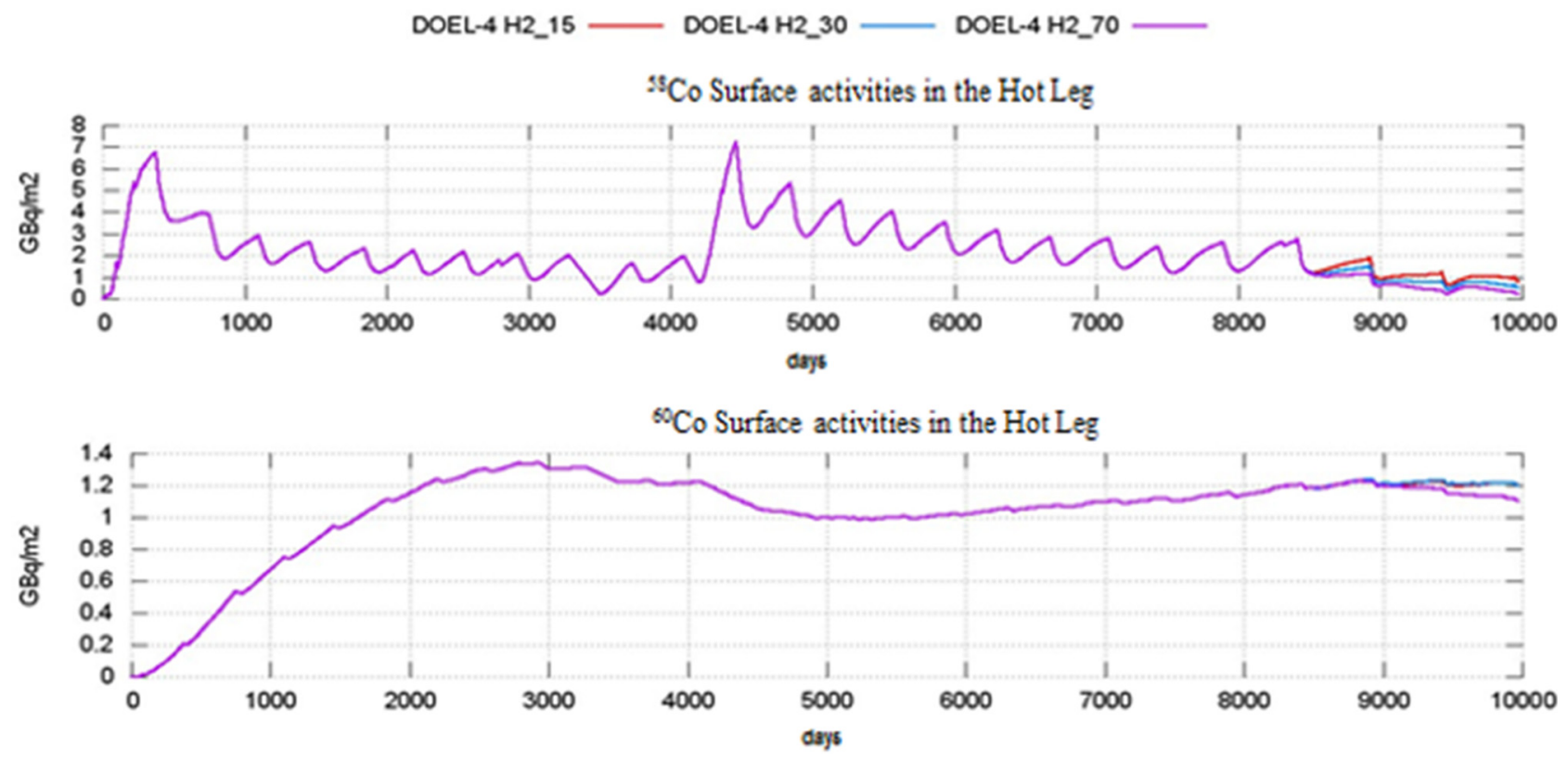

Fig. 4. OSCAR V1.3 calculation - Surface activities in the Hot leg region of DOEL-4.
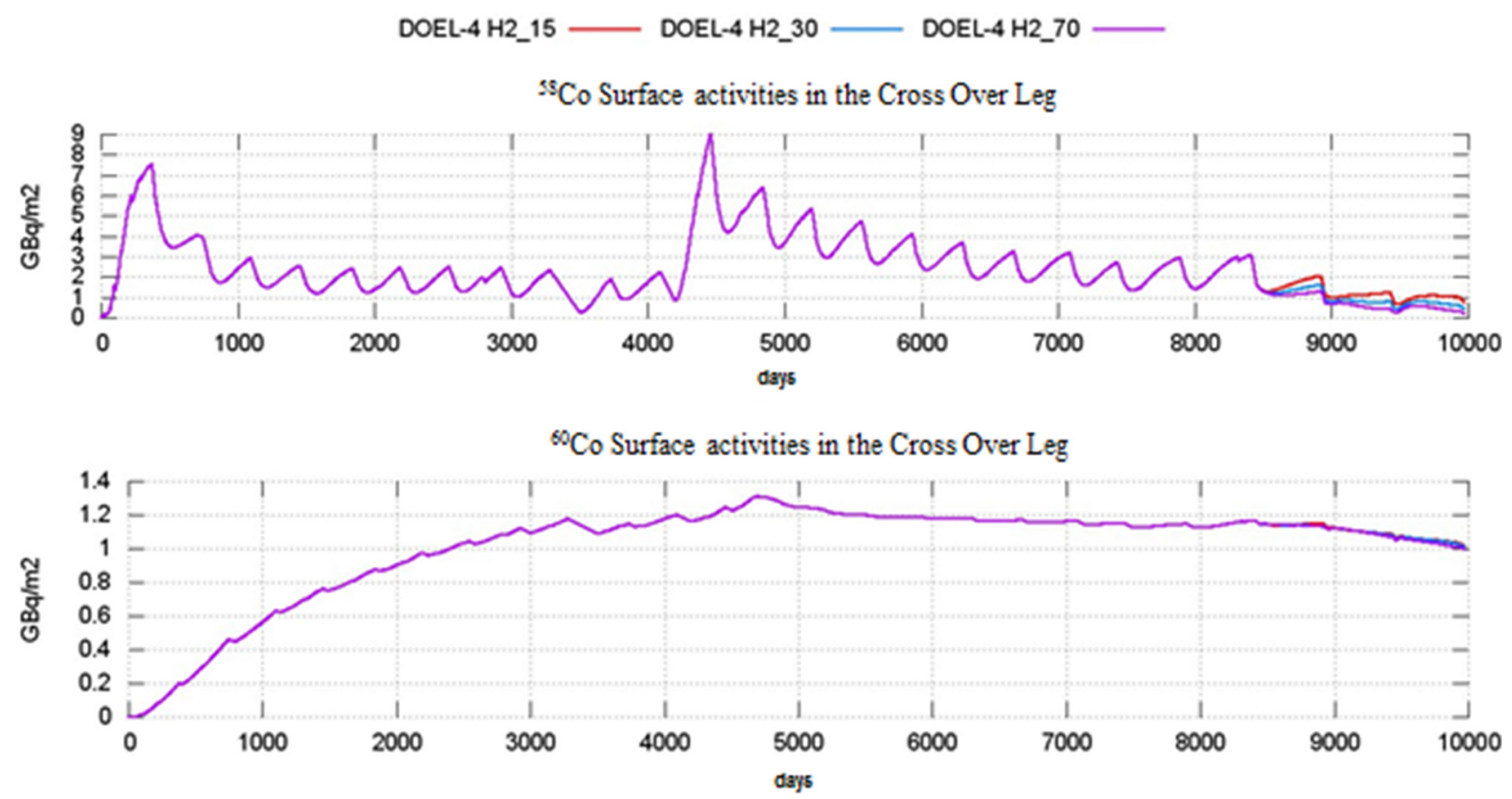

Fig. 5. OSCAR V1.3 calculation - Surface activities in the crossover leg region of DOEL-4.

On the contrary, an increase in the $\mathrm{DH}$ value up to $70 \mathrm{~mL} / \mathrm{kg}$, leads to smaller $\mathrm{Ni}$ equilibrium concentration and $\mathrm{Ni}$ concentration in solution are smaller. Ni concentration in solution is lower than the $\mathrm{Ni}$ equilibrium concentration in solution, and then $\mathrm{Ni}$ tends to dissolve from the deposit on the fuel rods into the reactor coolant.

When the DH concentration goes from 15 to $70 \mathrm{~mL} / \mathrm{kg}$, equilibrium $\mathrm{Ni}$ concentrations in solution and $\mathrm{Ni}$ concentrations in solution on the cold side of the steam generator tubing evolve (see Fig. 9).

Equilibrium $\mathrm{Ni}$ concentrations in solution and $\mathrm{Ni}$ concentrations in solution decrease when the DH increases (for DH concentrations of 15 and $30 \mathrm{~mL} / \mathrm{kg}$, Ni concentrations in solutions are equal).

For each DH values, Ni concentrations in solution are much lower than the equilibrium $\mathrm{Ni}$ concentrations in 

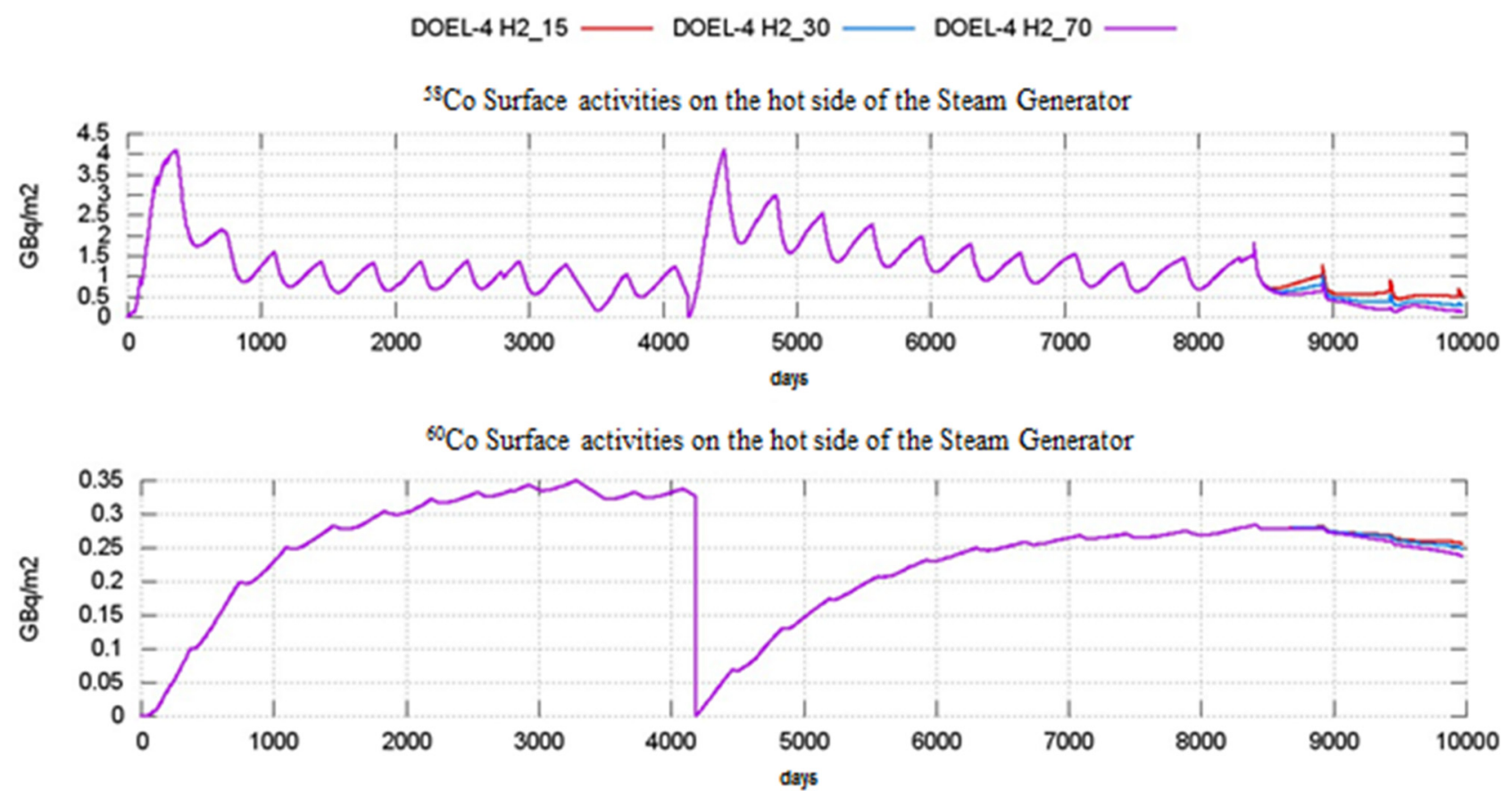

Fig. 6. OSCAR V1.3 calculation - Surface activities on the hot side of the steam generator tubing region of DOEL-4.
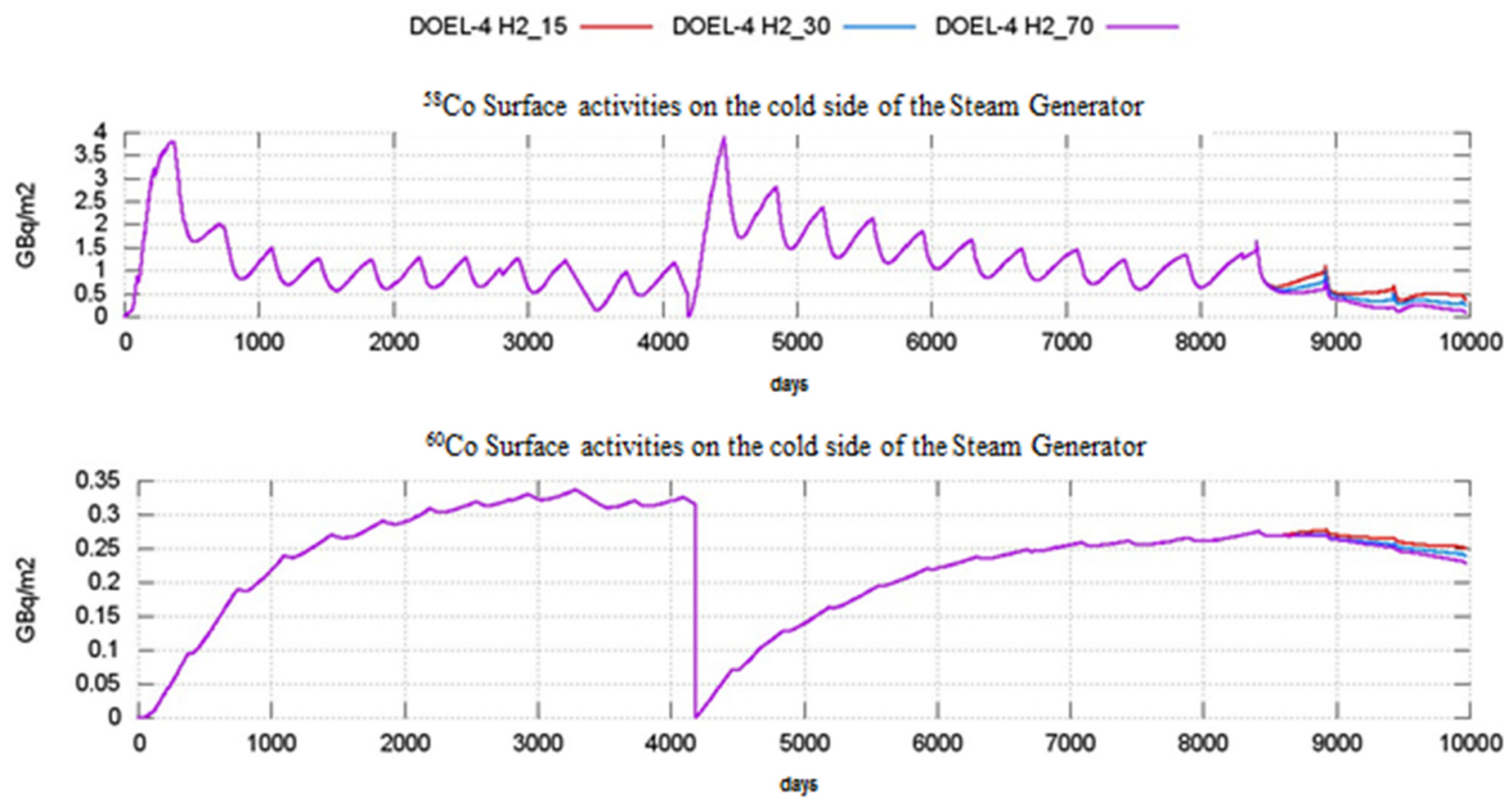

Fig. 7. OSCAR V1.3 calculation - Surface activities on the cold side of the steam generator tubing region of DOEL-4.

solution, and then $\mathrm{Ni}$ dissolves in the steam generator tubing in the three cases. An increase in the DH value induces a narrowing of the gap between equilibrium $\mathrm{Ni}$ concentrations in solution and $\mathrm{Ni}$ concentrations in solution and therefore a lower $\mathrm{Ni}$ dissolution in the $\mathrm{SG}$ tubing for higher DH values.
6 Comparison between the Co equilibrium concentrations and Co concentrations inside the core and steam generator tubing regions

Co equilibrium concentrations and Co concentrations in the hottest fuel region and the SG cold side region in 
Table 3. OSCAR V1.3 calculation - Relative variations of the deposited activities on the out of core surfaces compared to a $\mathrm{DH}$ value of $30 \mathrm{~mL} / \mathrm{kg}$.

\begin{tabular}{lll}
\hline & \multicolumn{2}{l}{$\begin{array}{l}\text { Out-of-flux surface } \\
\text { activities }\end{array}$} \\
\hline Variations $/\left[\mathrm{H}_{2}\right]=30 \mathrm{~mL} / \mathrm{kg}$ & ${ }^{58} \mathrm{Co}$ & ${ }^{60} \mathrm{Co}$ \\
End of cycle 25 & & \\
{$\left[\mathrm{H}_{2}\right]=15 \mathrm{~mL} / \mathrm{kg}$} & $+74 \%$ & $+4 \%$ \\
{$\left[\mathrm{H}_{2}\right]=70 \mathrm{~mL} / \mathrm{kg}$} & $-57 \%$ & $-4 \%$ \\
\hline
\end{tabular}

the case of a $\mathrm{DH}$ value of $70 \mathrm{~mL} / \mathrm{kg}$ are presented in Figure 10.

Co equilibrium concentrations are generally above Co concentrations in the hottest fuel region and SG cold side regions. As a result, Co tends to dissolve from the deposit/ outer oxide or slightly precipitate. This ${ }^{59} \mathrm{Co}$ that precipitates on the fuel rods is activated in ${ }^{60} \mathrm{Co}$, eroded and transported by the primary fluid, makes deposits on the out-of-flux surfaces.

Note that the peaks observed for the last three cycles correspond to the cold shutdowns.

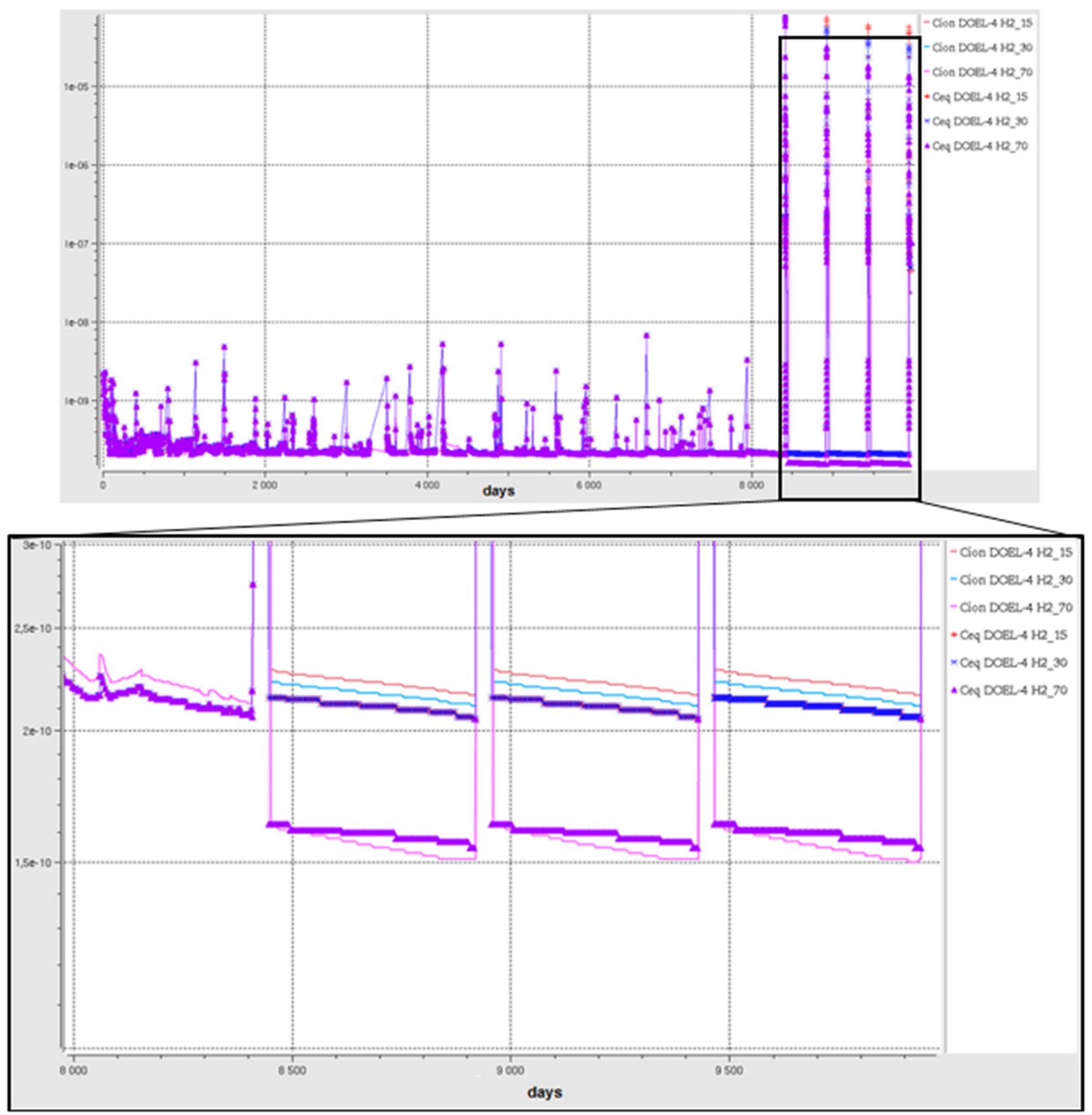

Fig. 8. OSCAR V1.3 calculation - Comparison between Ni equilibrium concentrations in solution (Ceq) and Ni concentrations in solution (Cion) inside the hottest core region. 


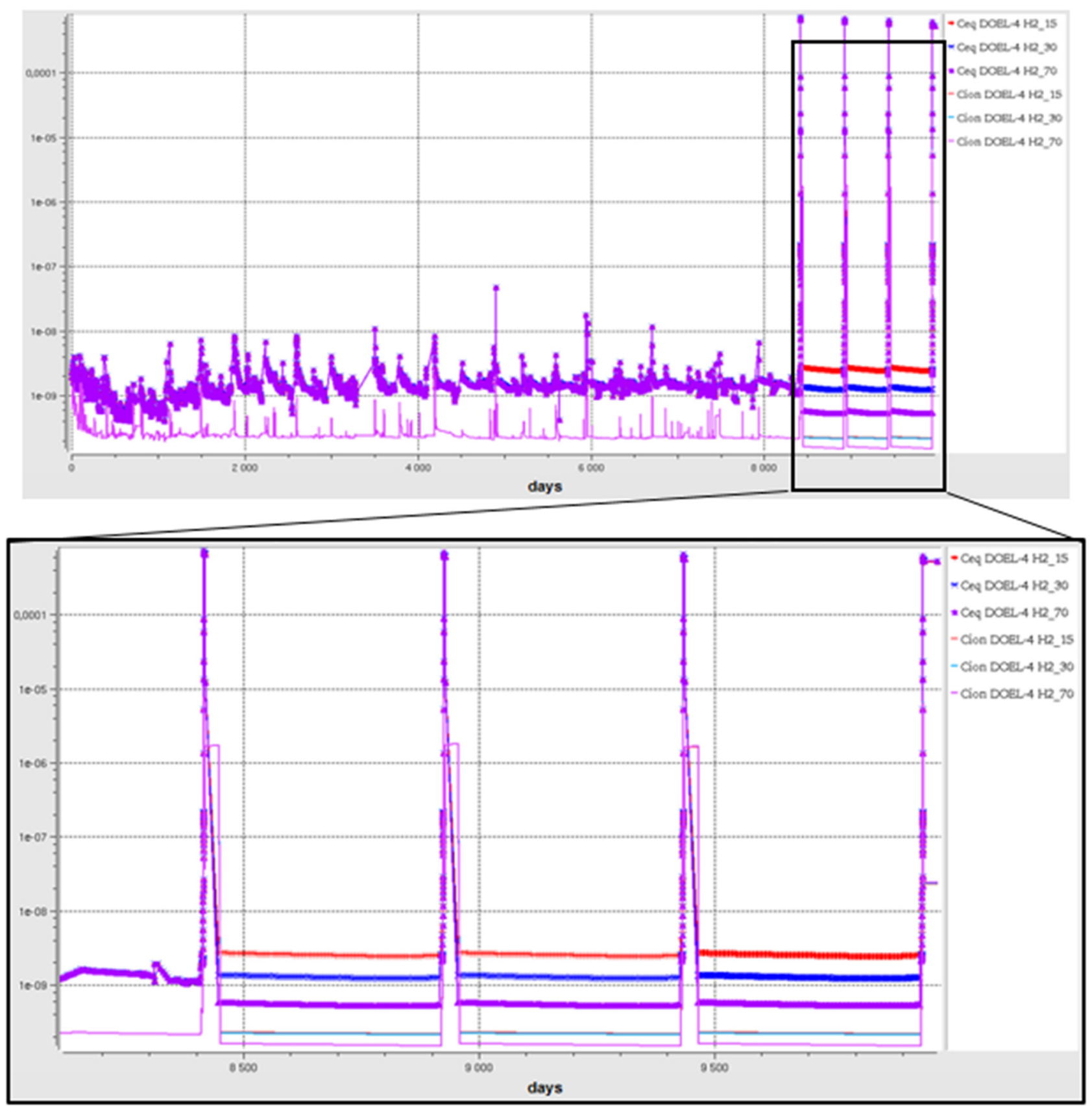

Fig. 9. OSCAR V1.3 calculation - Comparison between Ni equilibrium concentrations in solution (Ceq) and Ni concentrations in solution (Cion) inside the SG cold side region.

\section{$7 \mathrm{Ni}$ and Co dissolution versus corrosion release rate calculated in the steam generator region}

\subsection{Concerning $\mathrm{Ni}$}

$\mathrm{Ni}$ dissolution (from the deposit/outer oxide to the ions medium) and the corrosion release rate (directly from the metal to the ions medium) from the cold side of the steam generator tubing (for the three $\mathrm{DH}$ values 15, 30 and $70 \mathrm{~mL} / \mathrm{kg}$ ) are calculated and presented in Figure 11.
Clearly, Ni dissolution from the deposit and corrosion release in the steam generator region decrease when the $\mathrm{DH}$ increases. The $\mathrm{Ni}$ comes mainly from dissolution, as the dissolution rate is two orders of magnitude higher than the corrosion release rate.

\subsection{Concerning Co}

Co dissolution (from the deposit/outer oxide to the ions medium) and the corrosion release rate (directly from the metal to the ions medium) from the cold side of the steam 


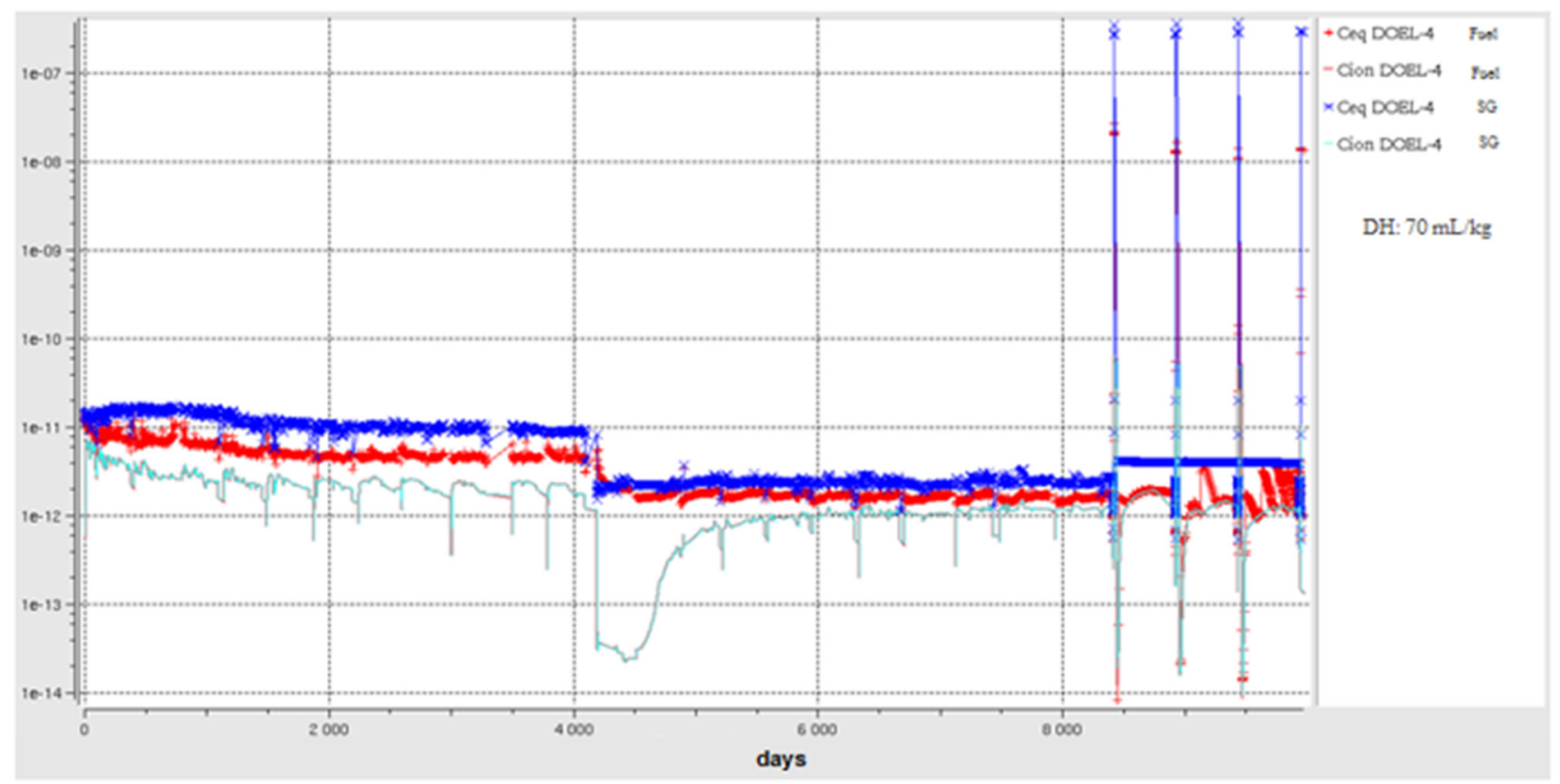

Fig. 10. OSCAR V1.3 calculation - Comparison between Co equilibrium concentrations (Ceq) and Co concentrations in solution (Cion) inside the hottest fuel and SG cold side regions with a $\mathrm{DH}$ value of $70 \mathrm{~mL} / \mathrm{kg}$.



Fig. 11. OSCAR V1.3 calculation - Ni dissolution versus corrosion release rate in the steam generator region for cycle 25 .

generator region (for the three $\mathrm{DH}$ values 15,30 and $70 \mathrm{~mL} / \mathrm{kg}$ ) are presented in Figure 12.

Co dissolution from the steam generator region increases with the DH concentration. On the other hand, the Co release rate from the steam generator region decreases when the concentration increases.
For a DH value of $70 \mathrm{~mL} / \mathrm{kg}$, the Co dissolution from the steam generator region is higher than for the other DH values while the corrosion release rate is the lowest one.

For $\mathrm{DH}$ values of 15 and $30 \mathrm{~mL} / \mathrm{kg}$, the Co comes mainly from the direct corrosion release of the steam generator tubing. 


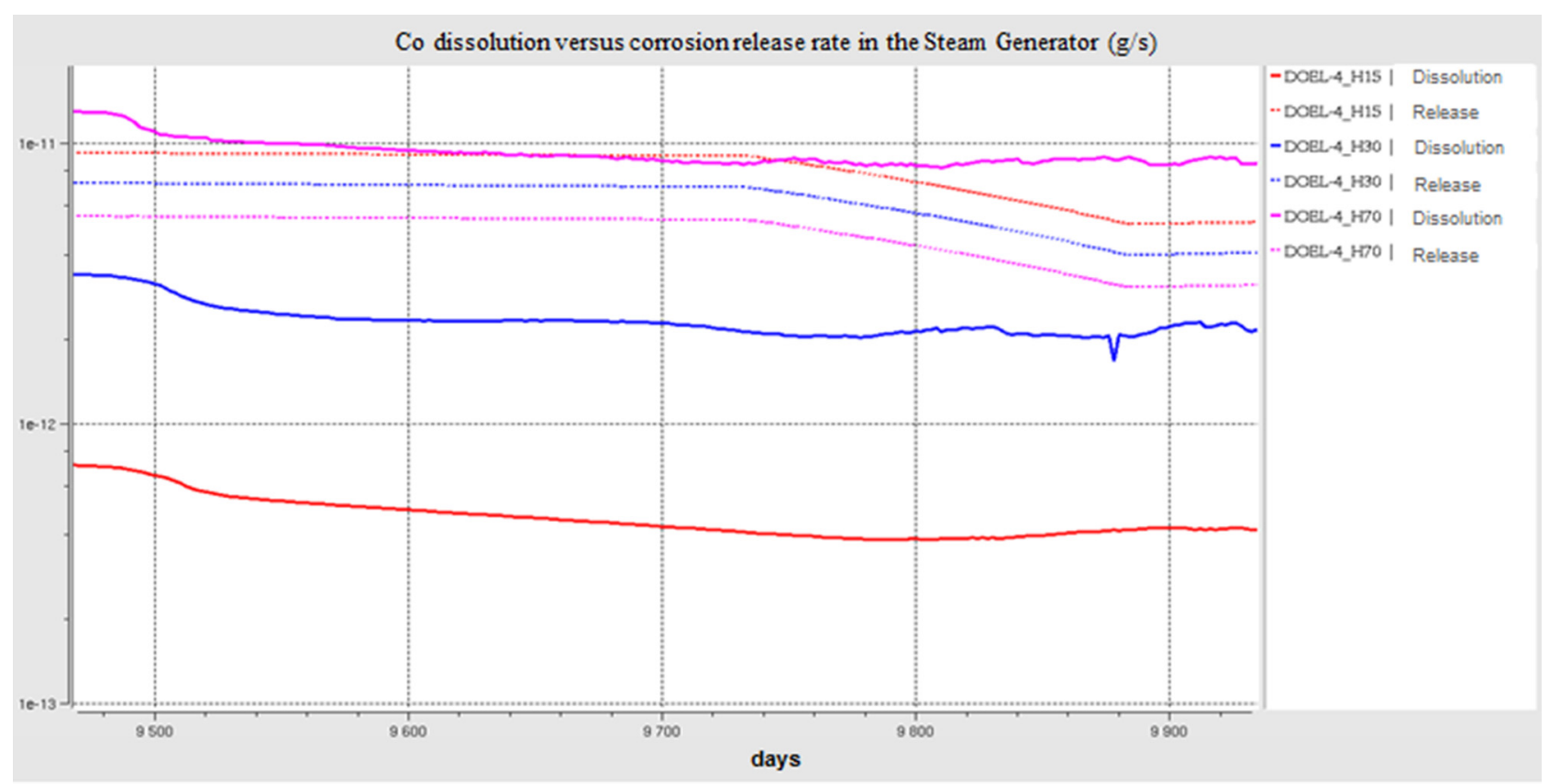

Fig. 12. OSCAR V1.3 calculation - Co dissolution versus corrosion release rate in the steam generator region for cycle 25 .

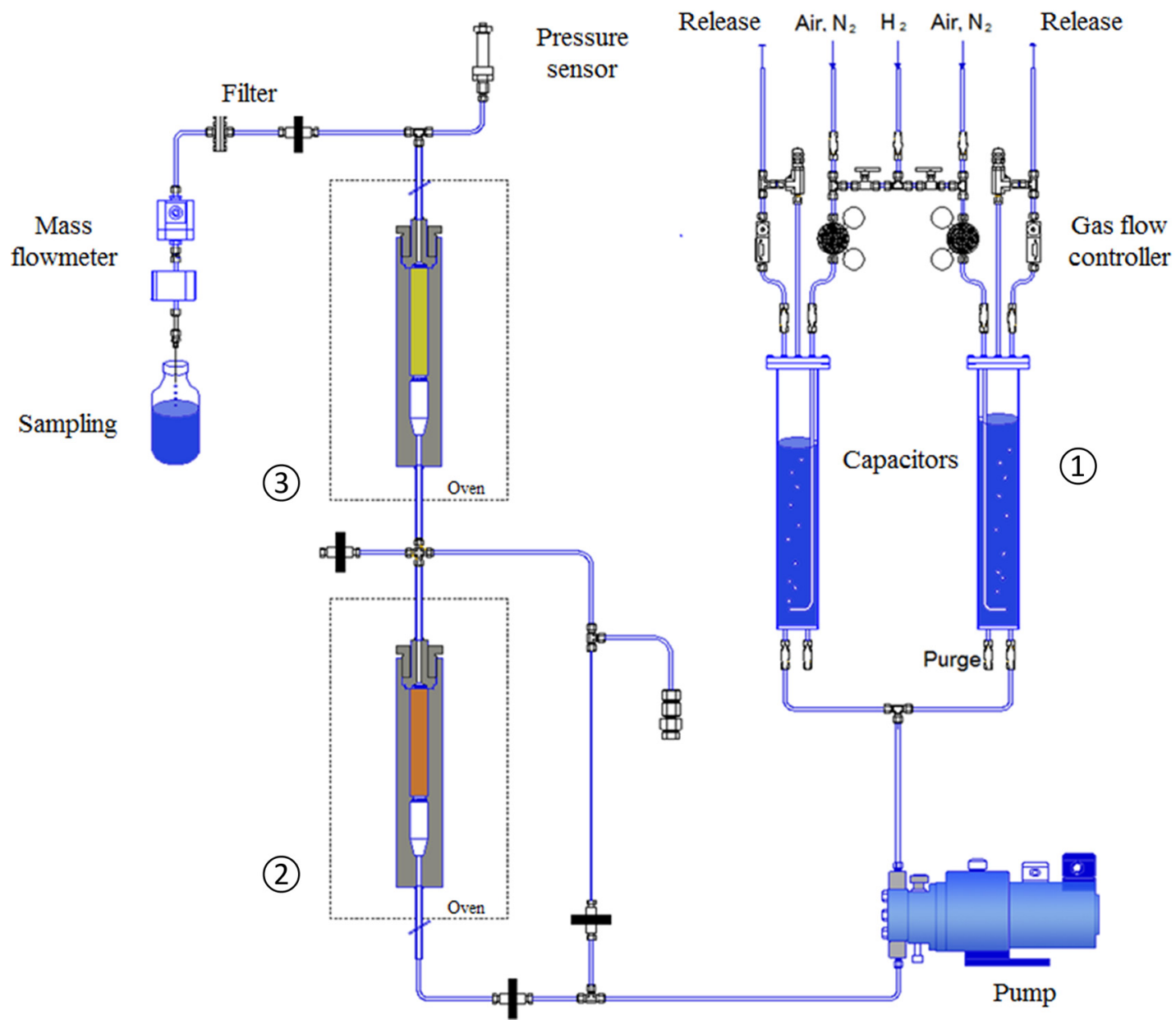

Fig. 13. DUPLEX device. 


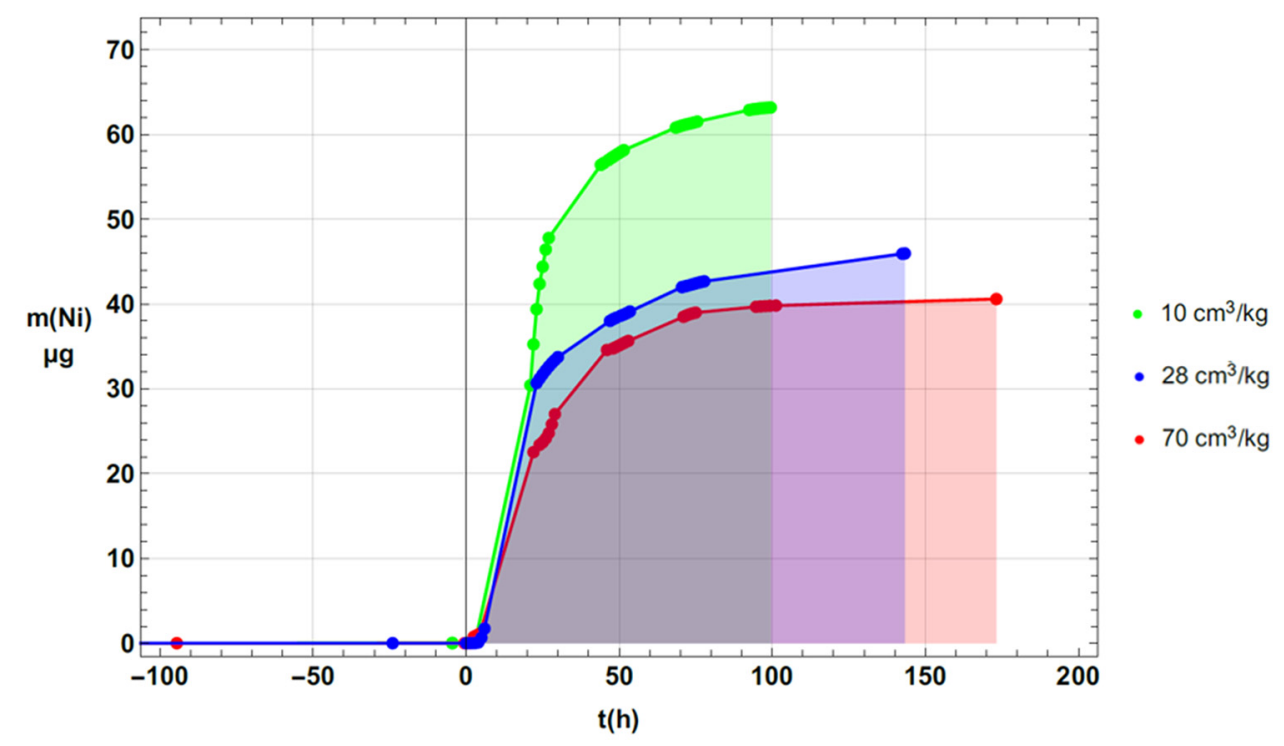

Fig. 14. DUPLEX experiments - Ni mass deposited on the core cell for various DH values.

\section{DUPLEX experiments}

The DUPLEX experimental device, which is based on the principle of EVA device [10], consists of:

- two titanium (TA6V) cells (1) (see Fig. 13) crossed by a steady-state and monophasic flow;

- the steam generator cell (2), set with a temperature of $270^{\circ} \mathrm{C}$, which reproduces the steam generator conditions and contains alloy 690 composed of $\mathrm{Ni}$;

- the core cell (3), set with a temperature of $340^{\circ} \mathrm{C}$, which reproduces the fuel cladding and contains pre-oxidized M5 alloy. This cell is dedicated to study the precipitation of the Ni corrosion product coming from the corrosion release of alloy 690 .

The elementary composition, especially $\mathrm{Ni}$ composition, of different solutions with different $\mathrm{DH}$ concentrations is measured by mass spectrometry.

DUPLEX experiments aim to study the influence of the DH value (here 10,28 and $70 \mathrm{~cm}^{3} / \mathrm{kg}$ ) on the Ni coming from the corrosion of alloy 690 in the steam generator cell and then its deposition on the core cell.

The Ni mass deposited on the core cell is given for the three DH concentrations in Figure 14. It is clear that the $\mathrm{Ni}$ mass decreases with increasing $\mathrm{DH}$ concentration. The decrease is even more pronounced when the DH goes from 10 to $28 \mathrm{~cm}^{3} / \mathrm{kg}$ than from 28 to $70 \mathrm{~cm}^{3} / \mathrm{kg}$.

Those experimental results are consistent with the OSCAR calculations shown in Figure 7. Indeed, Figure 7 represents surface activities on the cold side of the steam generator tubing for ${ }^{58} \mathrm{Co}$ coming from the activation of ${ }^{58} \mathrm{Ni}$. So, if the increase of the $\mathrm{DH}$ value leads to a decrease in the ${ }^{58} \mathrm{Co}$ surface activities, the variation has to be the same for ${ }^{58} \mathrm{Ni}$. This tendency is clearly confirmed by the Ni mass deposited on the core cell in Figure 14 .

\section{Conclusion}

For DOEL-4 PWR, OSCAR V1.3 calculations have shown that an increase in the DH concentration (from 15 to $70 \mathrm{cc} / \mathrm{kg}$ ) leads to a significant decrease of the ${ }^{58} \mathrm{Co}$ deposited activity and, to a negligible extent, of ${ }^{60} \mathrm{Co}$ deposited activity.

Concerning ${ }^{58} \mathrm{Co}$, this phenomenon is governed by the Ni equilibrium concentration in solution, which decreases in the SG region with increasing DH. This leads to a lower $\mathrm{Ni}$ dissolution and corrosion release from the steam generator with high $\mathrm{DH}$ values $(70 \mathrm{~mL} / \mathrm{kg}$ in this study) and then, after activation and transport to the out-of-flux surfaces, to a lower ${ }^{58} \mathrm{Co}$ contamination.

Concerning ${ }^{60} \mathrm{Co}$, calculated Co equilibrium concentrations in solution are generally above Co concentrations in solution in the fuel and the steam generator regions. As a result, Co tends to dissolve from the deposit/outer oxide or slightly precipitate.

The measured $\mathrm{Ni}$ deposited on the core cell in the DUPLEX experiment evolves in the same way as the calculated ${ }^{58} \mathrm{Co}$ deposited activity (resulting from the activation of ${ }^{58} \mathrm{Ni}$ in the fuel region). Indeed, the ${ }^{58} \mathrm{Co}$ deposited activity and ${ }^{58} \mathrm{Ni}$ mass decreases with increasing DH as observed, respectively, through OSCAR simulations and DUPLEX experiments.

Finally, one may recommend increasing the $\mathrm{DH}$ concentration in operating PWRs to reduce the ${ }^{58} \mathrm{Co}$ surface contamination.

\section{Author contribution statement}

All the co-authors mentioned in this article actively contributed to the work reported in this article and I sincerely want to thank them. Indeed, F. Dacquait (senior expert in corrosion products in reactors) and E. Tevissen (contamination project manager) brought all their 
knowledge in the radioactive contamination field and the simulation of the behavior of corrosion products in PWRs through the OSCAR code. D. You (senior expert in reactor chemistry) has performed the duplex experiments with thermodynamic and chemical conditions closed to those observed in PWRs and brought all of his knowledge in the reactor chemistry field. Finally, this article results from a collaboration with R. Lecocq and K. Schildermans from ENGIE through the simulation of DOEL-4, a Belgian unit. Indeed, the structure of the DOEL-4 primary circuit has been modelled through OSCAR by control volumes using the design data of the reactor.

\section{References}

1. P. Beslu, G. Frejaville, A. Lalet, A computer code PACTOLE to predict activation and transport of corrosion products in PWR, in Proceedings of the International Conference of Water Chemistry of Nuclear Reactors Systems 1, BNES, London, 1978, pp. 195-201

2. L. Di Pace, D. Tarabelli, D. You, Development of the PACTITER code and its application to the assessment of the ITER divertor cooling loop corrosion products, Am. Nucl. Soc. 34, 733 (1998)

3. F. Dacquait et al., Simulation of corrosion product transfer with the OSCAR v1.2 Code, in Nuclear Plant Chemistry Conference, Paris, 2012, pp. P1-24-193
4. J.-B. Genin, M. Benfarah, C. Dinse, M. Corbineau, Simulation of alpha contamination in PWR with the OSCAR Code, in Nuclear Plant Chemistry Conference, Sapporo, 2014, p. 10134

5. C.J. Wood, Comprehensive Nuclear Materials (Elsevier, Palo Alto, 2012)

6. H. Christensen, Fundamental aspects of water coolant radiolysis, SKI report 2006:16, 2006

7. S.H. Baek, H.-S. Shim, J.G. Kim, D.H. Hur, Effects of dissolved hydrogen on fuel crud deposition and subcooled nucleate boiling in PWR primary water at $328^{\circ} \mathrm{C}$, Nucl. Eng. Des. 345, 85 (2019)

8. D.L. Parkhurst, C.A.J. Appelo, User's guide to PHREEQC (version 2) - A computer program for speciation, batchreaction, one-dimensional transport, and inverse geochemical calculations, Report 99-4259, US Geological Survey, Denver, Colorado, 1999

9. G. Plancque, D. You, E. Blanchard, V. Mertens, C. Lamouroux, Role of chemistry in the phenomena occurring in nuclear power plants circuits, in Proceedings of the International Congress on Advances in Nuclear power Plants, ICAPP, 2-5 May 2011, Nice, France (2011)

10. D. You, S. Lefevre, D. Féron, F. Vaillant, Experimental study of concentrated solutions containing sodium and chloride pollutants in sg flow restricted areas, in Proceedings of the International Conference of Water Chemisty in Nuclear Reactor Systems, Avignon, France, April 2002, p. 8

Cite this article as: Mehdi Gherrab, Frédéric Dacquait, Dominique You, Etienne Tevissen, Raphaël Lecocq, Kim Schildermans, Influence of the dissolved hydrogen concentration on the radioactive contamination of the primary loops of DOEL-4 PWR using the OSCAR code, EPJ Nuclear Sci. Technol. 6, 7 (2020) 